\title{
Software de gestão da saúde da família: mapeando a colaboração em Engenharia de Software durante a estabilização de um ecossistema digital.
}

\author{
Fernando G. Severo, José M. Gonçalves, Andréa M. Magdaleno ${ }^{1}$, Cláudia M. \\ Werner, Henrique L. Cukierman \\ Programa de Engenharia de Sistemas e Computação - COPPE-UFRJ \\ Caixa Postal 68511 - Rio de Janeiro, RJ, 21945-970, Brasil \\ \{severo,jmsg,andrea,werner,hcukier\}@cos.ufrj.br
}

\begin{abstract}
Resumo. Neste trabalho, investigamos o processo de implantação de um sistema/software de apoio à estratégia da saúde da família em um bairro do municipio do Rio de Janeiro. Nesse sentido, procuramos compreender como se estruturam as redes de colaboração entre os atores que vêm negociando as decisões sobre a customização deste software. Utilizando a metodologia da Teoria Ator-Rede (TAR), mapeamos os registros desta colaboração durante a estabilização do ecossistema pesquisado. Além disso, buscamos conciliar e confrontar, simultaneamente, as hipóteses dos estudos em Colaboração em Engenharia de Software com os Estudos Ciência-Tecnologia-Sociedade (CTS), concluindo que existem oportunidades de diálogo entre ambos.
\end{abstract}

Abstract. In this paper, we investigate the software deployment process of the family health strategy support in a district of Rio de Janeiro. In this sense, we seek to understand how to structure the collaborative networks among the actors who have been negotiating decisions about the customization of this software. Using the methodology of Actor-Network Theory (ANT), we mapped this collaboration during the stabilization of the studied ecosystem. In addition, we attempt to simultaneously arrange and confront the hypotheses of the studies in Collaborative Software Engineering with Science and Technology Studies (STS), concluding that there are opportunities for dialogue between them.

\section{Introdução}

A saúde é reconhecida como um setor de extrema complexidade, que exige conhecimentos, equipamentos e estruturas de gestão sofisticados. Especificamente em relação às Tecnologias da Informação e Comunicação (TICs), estudos sobre os Sistemas de Informação em Saúde (SIS) mostram que os avanços tecnológicos da própria medicina e das TICs vêm configurando novas formas de gestão no setor (HAUX, 2005; FORNAZIN e JOIA; 2013).

No Brasil, o Governo Federal aponta a importância da saúde ao enquadrá-la como um setor estratégico do programa TI Maior ${ }^{2}$. Essa iniciativa disponibiliza recursos

\footnotetext{
${ }^{1}$ Pesquisadora financiada pelo CNPq, sob o processo n. 151158/2013-4.

${ }^{2}$ O Programa Estratégico de Software e Serviços de TI busca promover a integração de setores da economia (saúde, educação, defesa, óleo e gás e etc) em torno do segmento de aplicativos e serviços de
} 
financeiros para investimentos em SIS, estimulando a formação de ecossistemas digitais a partir da aglutinação de atores interdisciplinares e heterogêneos (centros de pesquisa de excelência, institutos de pesquisa e empresas privados e públicos), almejando, assim, à estabilização de redes em torno dos grandes desafios existentes nessas estruturas.

Neste trabalho, procuramos acompanhar mais de perto a customização de um desses SIS, um software proprietário de uma empresa estrangeira de eHealth $^{3}$, que oferece uma gama de produtos no setor de saúde, para apoiar as atividades da estratégia de saúde da família em um bairro do Município do Rio de Janeiro. Nosso foco, é entender como se estruturam, desestruturam e reestruturam as redes de colaboração que vêm estabilizando (ou não) as diversas versões deste software.

Procuramos dialogar com estudos que colocam e discutem conceitos e aspectos de colaboração em desenvolvimento de software, como comunicação, coordenação, memória e percepção (MAGDALENO, 2013; WHITEHEAD et al., 2010; ARAUJO et al., 2007; FUKS et al., 2003), em especial na relação dos usuários com a definição e validação dos requisitos (DAMIAN et al., 2010).

Nossa abordagem metodológica baseou-se no acompanhamento de casos práticos sobre a implantação do sistema, destacando a implementação da funcionalidade para tratamento dos dados sobre o Programa Bolsa Família (PBF). Nossas pesquisas pautaram-se, além das entrevistas com usuários que negociaram os requisitos de customização com os desenvolvedores ${ }^{4}$, no acesso às funcionalidades do sistema e rastros da comunicação (como e-mails, apresentações e documentos de requisitos) que foram deixados no processo, ainda em fluxo, de construção deste aplicativo.

Para acompanhar as customizações no SIS alvo desta pesquisa, utilizamos as ferramentas metodológicas da Teoria Ator-Rede (TAR), que são capazes de descrever e mapear a complexidade de um ecossistema que envolve as relações entre uma empresa privada sem fins lucrativos, uma fundação/centro de pesquisa de excelência e uma empresa multinacional de eHealth e seus respectivos elementos heterogêneos (papeis gestores, agentes de saúde, desenvolvedores, artefatos - requisitos e código fonte e equipamentos - computadores e tablets). Procuramos, assim, seguir tanto os atores humanos como os não-humanos nas negociações e traduções de seus diversos interesses (CALLON, 1986; LATOUR, 2000).

\section{A construção da solução}

No Brasil, a atenção primária, ou básica, serve de porta de entrada para todo o Sistema Único de Saúde (SUS), oferecendo o primeiro contato às pessoas que necessitem de qualquer um de seus serviços. Dentre os modelos de atenção básica existentes, o Município do Rio de Janeiro optou pela Estratégia de Saúde da Família (ESF), que conta com equipes multidisciplinares, acompanhando de forma contínua as famílias que

TI, através do desenvolvimento de software e soluções de alta complexidade e tremendo impacto econômico e social (fonte: http://timaior.mcti.gov.br/ em 07/02/2014).

3 eHealth, ou seja, eSaúde é o termo adotado e recomendado pela Organização Mundial de Saúde (OMS).

4 Foram realizadas 3 entrevistas; em 03/12/2013, com a primeira coordenadora do projeto de customização; em 10/12/2013, com o atual coordenador; e em 17/12/2013, com 2 técnicos administrativos de uma das clínicas de saúde da família, que participam da negociação dos requisitos. 
moram em determinada área de abrangência. Na cidade, a administração de cada território é feita através da contratação de Organizações Sociais de Saúde (OSSs) ${ }^{5}$.

Quando, em 2009, uma fundação pública estruturou uma OSS para pleitear, junto à Secretaria Municipal de Saúde e Defesa Civil (SMSDC), a gestão da ESF em um bairro do município, uma das questões mais críticas era o suporte de sistemas de controle das informações sobre o cadastro das famílias e registro do prontuário de cada pessoa acompanhada pelas equipes de saúde da família ${ }^{6}$. Segundo os entrevistados, a fundação já tinha um projeto institucional para utilização de um software de prontuário eletrônico de uma empresa estrangeira de eHealth, com o intuito de padronizar as informações sobre os pacientes de todas as suas unidades assistenciais. Assim, ficou determinado que a customização deste software seria a solução a ser implantada para o suporte das equipes de saúde da família.

\subsection{Enredando os atores na customização do prontuário eletrônico}

A TAR usa o conceito de problematização como primeira etapa no acompanhamento do processo de construção de um fato científico ou artefato tecnológico. A estabilização do processo de construção de um produto de software é resultado da formação de uma rede e requer a justaposição de atores heterogêneos (humanos e não humanos, por exemplo, um gestor e um software), que depende da possibilidade de formação de alianças, e, consequentemente, da convergência de interesses num fluxo comum.

A problematização consiste nesse duplo movimento: identificar o conjunto dos atores e suas identidades e, concomitantemente, estabelecer um Ponto de Passagem Obrigatório (PPO) na rede de relacionamentos que vai sendo construída (CALLON, 1986, p. 6). No caso estudado, o sucesso na implantação do prontuário eletrônico passou a ser o PPO (Figura 1) para o alinhamento dos diversos interesses: 1) a fundação pretendia transformá-lo no prontuário padrão de suas unidades; 2) para a empresa estrangeira, a consolidação do uso de seu software para a saúde da família na fundação abriria as portas para o mercado brasileiro; 3) a SMSDC também buscava um protocolo padrão que facilitasse a consolidação das informações para gestão da atenção básica; 4) a OSS necessitava de um sistema que desse o suporte para o acompanhamento dos indicadores e metas do contrato de gestão; e 5) as equipes de saúde da família precisavam agilizar o cadastramento e melhorar o acesso às informações dos pacientes, que era precário nos prontuários em papel.

Para a implantação da solução, foi montada uma equipe que definiria as diversas informações e templates das telas específicas para a ESF. O grande desafio era viabilizar a colaboração entre os diversos atores envolvidos: de um lado havia uma equipe da empresa prestadora de serviços (OSS) vinculada à fundação, composta pelos coordenadores do projeto, pelos agentes comunitários de saúde (ACS) e pelo pessoal administrativo; do outro, estava uma empresa privada de eHealth com seus gerentes, consultores, desenvolvedores, engenheiros de software e analistas de requisitos.

\footnotetext{
5 As OSS's são empresas de finalidade específica contratadas pela prefeitura para fazer a gestão terceirizada da atenção básica na cidade. A remuneração das OSS, pelo município, está condicionada ao cumprimento de metas, em determinados indicadores de saúde, pré-acordadas anualmente entre as partes. ${ }^{6} \mathrm{O}$ bairro estudado é dividido em 13 sub-regiões, que contam, cada uma, com sua equipe de saúde da família. Há outra equipe que acompanha a população de rua. A cobertura total é de cerca 11 mil famílias e 37 mil pessoas. A região conta com duas unidades de saúde onde as equipes estão alojadas.
} 


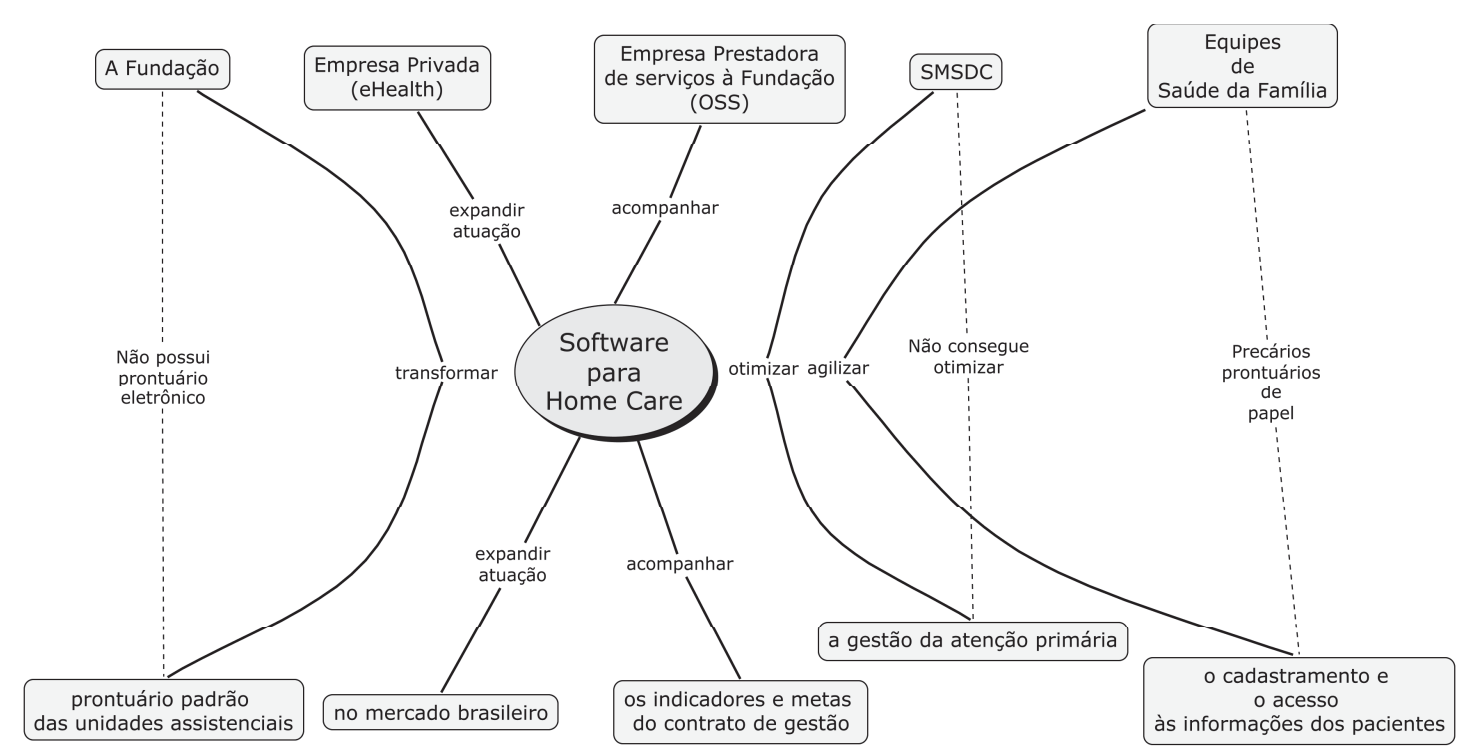

Figura 1: Produtos de software para Home Care, o Ponto de Passagem Obrigatório (PPO)

Para que a colaboração consiga se estabelecer, é necessária a união de esforços na construção deste software. A OSS, além de acompanhar os indicadores e metas do contrato de gestão, precisa gerir as equipes de saúde e acolher toda a micro-área daquela região: construir um software pode ser a solução deste desafio. A empresa de eHealth, além de vender seus prontuários eletrônicos, precisa aumentar seu portfólio de produtos e se adequar às particularidades do sistema de saúde brasileiro (Figura 2). A discussão não é meramente de ordem comercial, não se trata apenas de vender um software, pois este ainda nem existe. Realizar este software consiste em fazer uma tradução ${ }^{7}$, ou seja, antes que uma empresa de eHealth e uma OSS se disponham a colaborar entre si, faz-se necessário uma agregação de interesses distintos (LATOUR, 1996, p. 137).

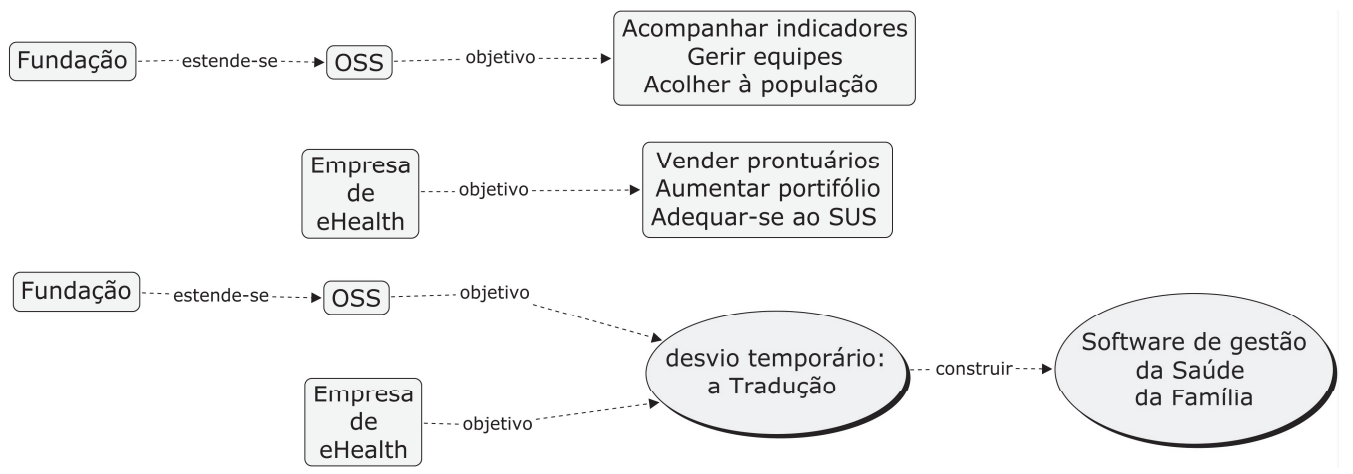

Figura 2: Operação de Tradução

O importante na operação dessa tradução não é apenas a mescla de interesses, mas a composição de um novo consórcio: um laboratório partilhado para a construção de um software. E ainda, o objetivo inicial geralmente não é alcançado de forma integral pelas partes envolvidas. "Há uma derivação, uma discrepância, um deslocamento que podem ser, conforme os casos, ínfimas ou infinitas" (LATOUR, 1996, p. 138). Por isso,

\footnotetext{
${ }^{7}$ Latour (2000, p. 194) utiliza o duplo sentido do inglês translation para indicar que uma tradução envolve tanto novas interpretações e sentidos dos objetivos originais dos atores, quanto a própria translação de interesses em direção a novos objetivos.
} 
a coordenação das atividades entre os diversos colaboradores é necessária para que os esforços de trabalho individual e de comunicação não sejam desperdiçados, em especial, quando as atividades são interdependentes (HANSEN, 2009).

\subsection{Apertando os laços de comprometimento}

No início do projeto, o software de eHealth não atendia as necessidades da saúde da família. Além de seu prontuário ser direcionado para ambientes hospitalares, o que demandaria muitas alterações para adequação à atenção básica, não havia nenhum produto para cadastro das famílias, nem para o controle das visitas. Tratar estas questões era fundamental para manter o comprometimento dos futuros usuários do sistema, como as equipes de ESF e os gestores da OSS. A empresa de eHealth buscou, então, uma parceria com uma empresa brasileira, que já tinha um produto mais adequado ao cadastro e controle de visitas. Outra ação, que reforçou o comprometimento da SMSDC com o projeto, foi a proposta de disponibilizar esta solução de sistemas de eHealth às demais unidades de saúde da família da região, mesmo àquelas cuja gestão era feita por outras OSSs. Esses movimentos, que por um lado reforçaram a solução e o comprometimento dos atores, tornaram mais complexa a rede de participantes, aumentando a importância de aspectos de colaboração para a estabilização deste produto de software. A primeira líder do projeto centralizou a coordenação e precisou ajustar as regras de comunicação, reconfigurar equipes e priorizar as entregas, para prevenir que a formação daquele ecossistema (cadeia de valor da saúde) se desfizesse.

Callon (1986, p. 8) explica que a problematização é uma etapa hipotética sobre um provável posicionamento dos atores, destacando que a realidade é um processo em constante negociação. Em outras palavras, a determinação da identidade dos atores é precária, podendo haver desvios de interesses, o que na TAR é identificado como o processo de dissidência ou traição. Uma vez definida a problematização, segue-lhe uma nova etapa, o interessamento, na qual diversas ações são envidadas no sentido de fixar os atores em torno do interesse comum, evitando, assim, as dissidências.

Apesar do produto final de um software ser um código extremamente formal, as definições de requisitos para chegar até ele precisam passar por discussões que utilizam linguagem natural, não estruturada. Além disso, fatores como distância física, ou diferenças socioculturais, podem dificultar ainda mais a comunicação (WHITEHEAD et al., 2010). No projeto, tais fatores indesejados precisavam ser mitigados. Além das reuniões presencias com as equipes, foram utilizados contatos via Skype e e-mails.

\subsection{Inscrevendo a consolidação do novo software na saúde da família}

As ações de interessamento, se bem sucedidas, geram, nos termos da TAR, o alistamento dos atores (CALLON, 1986, p. 10). Nessa etapa, as inscrições sobre o comprometimento dos participantes vão deixando seus rastros. Depois de muitas discussões, encontros (presencias e via Skype), e-mails, conflitos, artefatos de requisitos, estabilizações, implementações e testes, as primeiras versões estavam prontas para a "prova de realidade". Um produto para a saúde da família, pelo menos para a região em questão, já tinha evoluído de uma promessa ou desejo para um artefato em forma de códigos de programa.

Segundo relato dos entrevistados, mesmo com desgaste, as relações de colaboração entre os diversos atores foram se estabilizando. A interlocução entre a empresa estrangeira de eHealth melhorou com a fixação de uma gerente no Brasil, que 
conquistou a confiança da equipe da OSS. Além disso, as empresas parceiras se aproximaram, melhorando a colaboração entre ambas e garantindo uma melhor integração dos sistemas. O módulo de cadastro e controle de visitas começou a ser utilizado em outubro de 2010. Dois meses depois, o módulo do prontuário iniciou a operação. Durante 2011, novas funcionalidades foram implementadas e a solução foi estendida para outras unidades, geridas por outra OSS, em outros bairros.

\subsection{Mobilização dos atores: os porta-vozes falam por seus representados?}

Mas quem fala por quem nessa rede? Quem defendia o ponto de vista dos membros das equipes de saúde da família, principais usuários dos templates? Quem negociava a padronização de informações para a gestão da SMSDC? Quem falava pelos interessados finais, os pacientes da atenção básica, cuja participação nas decisões de gestão da saúde é determinada pela Constituição ${ }^{8}$ ? Na TAR, há um termo para descrever esta situação: porta-voz. Os porta-vozes "falam" por coletividades de atores humanos e não-humanos.

Da mesma forma, em alguns estudos de colaboração no desenvolvimento de software, também são questionados aspectos sobre a construção de requisitos de sistemas. Quantas pessoas trabalham em ou se comunicam sobre que requisitos? Há mais pessoas se comunicando sobre um determinado requisito do que as pessoas alocadas para trabalhar nele? Os que necessitam de coordenação estão sendo coordenados na prática? A distância influencia a comunicação na rede de colaboração? Existem membros-chave que intermediam o fluxo de informações sobre um requisito? (DAMIAN, et al., 2010). Latour responderia a estas questões com outras indagações:

Como em $O$ príncipe, de Maquiavel, a construção progressiva de um império é uma série de decisões quanto a alianças: com quem posso colaborar? Quem devo excluir? Como posso obter a fidelidade deste? E aquele, será confiável? Esse porta-voz é digno de crédito? Mas o que não ocorreu a Maquiavel é que essas alianças podem transcender os limites existentes entre seres humanos e "coisas" (LATOUR, 2000, p. 206).

Como se desenrolaram e ainda se desenrolam as alianças deste projeto de desenvolvimento de software? Poderíamos dizer que as traduções de interesses do início do projeto foram mantidas? Primeiramente, é preciso lembrar que a "rede" associada a este estudo não é uma estrutura fixa, mas um processo contínuo em transformação em que se constituem estabilizações transitórias, em função de ações práticas, alianças e decisões que vão sendo tomadas. Acompanhando essas transformações podemos identificar que, em relação aos interesses iniciais: 1) a fundação reforçou sua estratégia de fazer do prontuário eletrônico o padrão em suas unidades; 2) a empresa de eHealth consolidou um produto para a ESF, incluindo um novo módulo para uso de tablets (software para Home Care); 3) a SMSDC se afastou do ideal de uma solução única, pois a outra OSS abandonou o software estrangeiro e adotou um aplicativo brasileiro, assim traduzindo um momento de traição; 4) a OSS foco deste estudo de caso vem conseguindo resolver as questões de gestão do seu contrato com a prefeitura através da

\footnotetext{
${ }^{8}$ A estrutura básica da saúde é definida no seguinte artigo da Constituição Brasileira.

Art. 198 As ações e serviços públicos de saúde integram uma rede regionalizada e hierarquizada e constituem um sistema único, organizado de acordo com as seguintes diretrizes:

I - descentralização, com direção única em cada esfera de governo;

II - atendimento integral, com prioridade para as atividades preventivas, sem prejuízo dos serviços assistenciais;

III - participação da comunidade.
} 
parceria com a empresa de eHealth; 5) as 14 equipes de saúde da família do bairro conseguiram melhorar seu trabalho, eliminando os problemas dos controles em papel.

\section{A "percepção" da colaboração pelo olhar sociotécnico}

Após mostrarmos as ferramentas metodológicas que utilizamos para descrever os atores que performam nossa rede e a forma como esses colaboram ou não no desenvolvimento de software, vamos ampliar o "zoom" sobre esta trama, descrevendo a construção de um artefato de software específico para o pacote de produtos da empresa de eHealth. De fato, vamos descrever o desenvolvimento de um artefato que facilita o trabalho dos ACSs, ou ainda, que simplifica a gestão do contrato pela OSS, além de garantir o direito aos serviços sociais básicos da população atendida. Em outras palavras, descreveremos a construção de um código que cresce em número de linhas motivado não apenas pela força de um programador sentado sozinho numa mesa de escritório no exterior, mas também pelas forças dos demais interessados que convergem para a construção deste artefato. A ação situada que vamos acompanhar aborda a seguinte questão: como uma circular municipal se transforma num produto de software? Para respondê-la, lançamos mão de um estudo de caso: a implantação das condicionalidades do PBF nos módulos de cadastro de visitas e Home Care do software de eHealth.

Em agosto de 2013, a SMSDC emitiu uma circular destinada às OSSs que fazem uso de prontuários eletrônicos, comunicando a utilização exclusiva das bases de dados eletrônicas dessas empresas como fonte de informações referentes ao acompanhamento das condicionalidades de saúde para os beneficiários do PBF. Na prática, isso significa que duas empresas, a OSS da fundação e a de eHealth, vinculadas à mesma rede de atores, deveriam construir um "pedaço" de software, que precisava atender às exigências de um sistema de informação. Basicamente, esta circular exigia da equipe da OSS o envio mensal de um arquivo que deve ser exportado da base de dados do módulo de cadastro do software de eHealth. Para o envio dessas informações, são necessárias a customização desses campos no sistema de acolhimento e visitas e a atualização das informações sobre as condicionalidades das pessoas daquele território. Portanto, a OSS e a empresa de eHealth têm que trabalhar em conjunto.

Antes dessa circular entrar em vigor, tanto o módulo Home Care (software instalado num tablet, utilizado pelos ACSs nas visitas domiciliares) como o módulo de registro de visitas possuía apenas um campo onde era possível informar se a família recebia ou não o benefício do PBF. A baixa importância desse campo era evidenciada por sua localização numa aba (tela) denominada "Outras Informações".

Este software de eHealth deve comportar informações avançadas não somente porque ele articula o trabalho dos diversos atores (em especial dos ACSs), mas também para garantir um benefício às pessoas que necessitam desse apoio. Por isso, aquilo que era um cadastro básico no sistema agora deveria se transformar num sistema mais sofisticado. A partir desse momento, iniciaram-se dois trabalhos em paralelo: a sincronização entre as bases do sistema de informação local de eHealth e do DATASUS $^{9}$ (para validação das pessoas beneficiárias) e a construção dos novos templates. No fim de agosto, o atual coordenador e um técnico de TI da OSS enviaram o

\footnotetext{
${ }^{9}$ O DATASUS é o Departamento de Informática do SUS, responsável pela informatização no SUS, Fonte: (http://www2.datasus.gov.br/DATASUS/index.php?area=01) - acesso em 29/12/2013
} 
primeiro e-mail à gerente de projetos da empresa de eHealth, relatando os entendimentos da reunião entre eles e a representante da Coordenação da Saúde da Família. Resumidamente, neste e-mail, eles apresentaram as demandas da SMSDC, relatando as inconsistências nos relatórios extraídos da base do sistema e alertaram sobre as consequências da extração incorreta (destaque na Figura 3) dos relatórios do PBF.

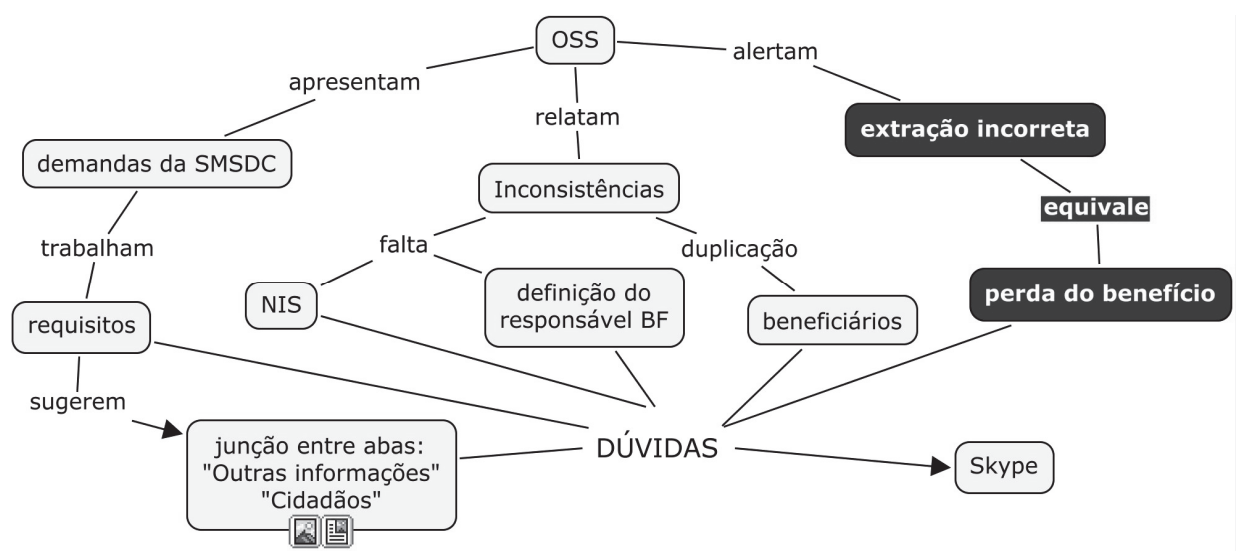

Figura 3: O início da colaboração na customização do PBF no software

Eles, também, aproveitaram este e-mail para enviar, em anexo, um requisito organizado (Figura 4), no qual sugeriram a junção entre as telas "Cidadãos" e "Outras Informações".

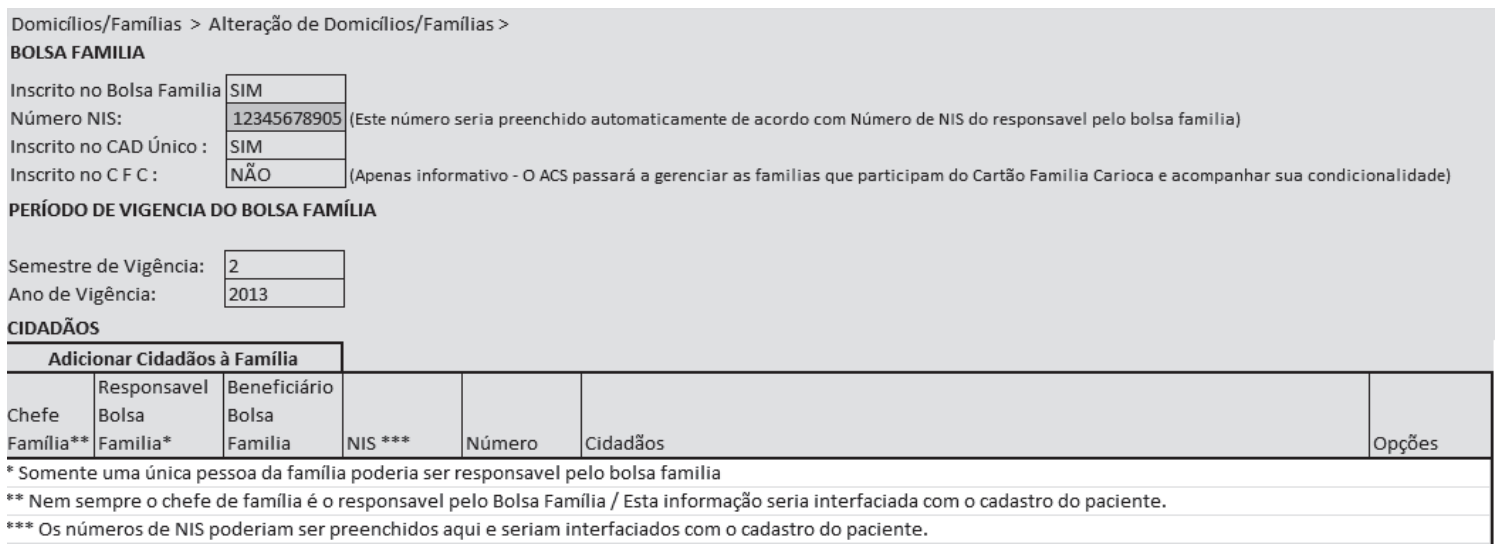

Figura 4: Requisito de software

Ao produzir o artefato de software, a equipe de TI da OSS (formada por um técnico administrativo, uma ex-ACS e coordenada por um bacharel em arquivologia) desempenha a função de analista de requisitos, o que no início nos surpreendeu. Com o passar das entrevistas a surpresa cedeu lugar a uma constatação óbvia: parte daquele time trabalhava lado a lado (presencialmente ou a distância) com os desenvolvedores da empresa de eHealth (no Brasil ou no exterior) desde 2010. Segundo suas palavras, eles são parceiros dos desenvolvedores no design dos requisitos, das telas e dos templates. Finalizando esse contato, a equipe da OSS terminou o e-mail com um, aparentemente, simples "Caso haja alguma dúvida, poderemos conversar pelo Skype", que, no entanto, desencadeia uma sucessão de trocas de comunicação. Entre agosto e novembro, a coordenação da OSS mobilizou uma força tarefa das equipes da ESF com o intuito de tornar o banco de dados do módulo de registro de visitas familiares o mais fiel possível. Foram cerca de 11 trocas de e-mails, nos quais a equipe de TI da OSS se esforçou para: 
1) negociar com a gerente de projeto e a consultora de implementação da empresa de eHealth uma extração da base indexada pelo NIS (Número de Identificação Social); 2) engajar os ACSs na árdua missão de validar e coletar todas as informações sobre as famílias de sua região. De certa forma, esse engajamento já existia, pois o ACS, também morador local, sabe que o benefício é crítico para aquelas pessoas. Simultaneamente, neste período, a equipe da empresa de eHealth (no exterior) iniciou o desenvolvimento do código para os dados do cadastro. Ainda em novembro, a consultora de implementação da empresa (no Brasil) enviou um e-mail à coordenação de TI da OSS com a primeira versão da documentação da release do produto em dois anexos: um contendo as novas funcionalidades pertinentes ao uso administrativo (pelos coordenadores do projeto), sendo o outro destinado aos ACSs. Após 15 dias de testes e validações com alguns usuários do sistema, a empresa de eHealth disponibilizou um guia de formação dos usuários e as releases do módulo de registro de visitas/atendimentos e do módulo Home Care (Figura 5).
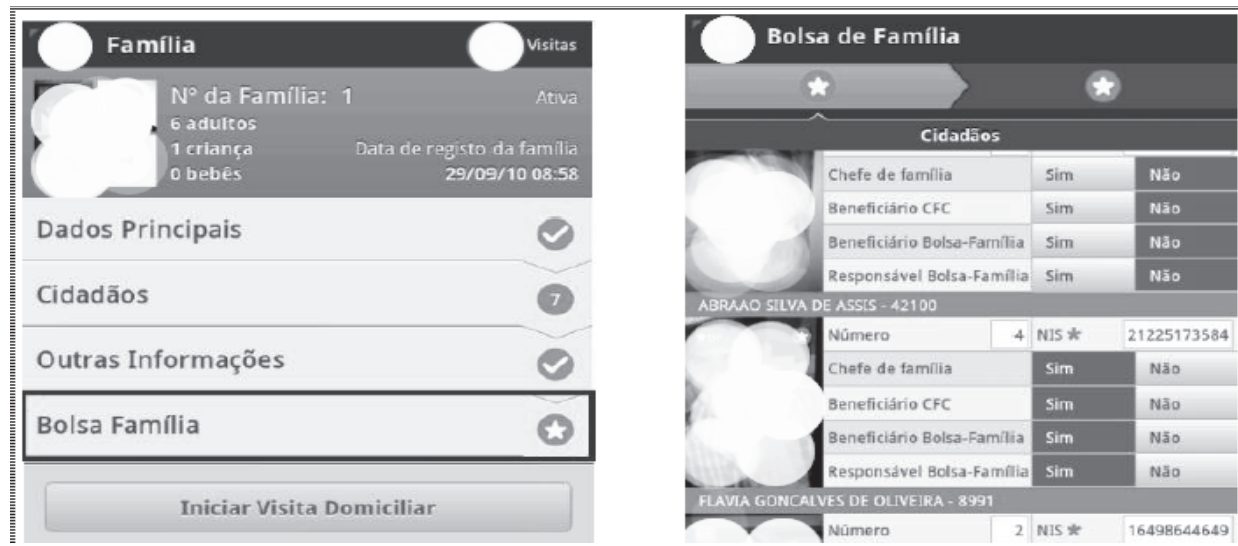

Figura 5: Telas de exemplos do módulo Home Care aprovadas pela OSS

Desde a circular saída do gabinete da SMSDC até a atualização de versão em cada tablet utilizado pelos ACSs, transcorreram três meses do processo da construção de um software. Nossa história, que percorreu distâncias continentais entre o interior e o exterior do país, é simetricamente uma história social das ciências e das tecnologias e uma história científica e tecnológica da sociedade. Nossa investigação pretende dar conta dos métodos responsáveis pela compreensão de que um artefato (um software) é um conteúdo sociotécnico, e não apenas técnico, por isso se forma a partir de elementos "técnicos" e "sociais", não-humanos e humanos. Para isto, mapeamos os registros de colaboração entre esses elementos heterogêneos, durante a estabilização do ecossistema deste estudo (Figura 6).

Quando o líder de projeto da OSS esboça um requisito, isso significa que, ao mesmo tempo, está trabalhando para conseguir: a prestação de contas junto ao munícipio, a instalação da release em um tablet, o respeito das outras OSSs (seus pares/colegas), a exportação de arquivo extensão $c s v$, a confiança de uma população e mais linhas de código para um software. 


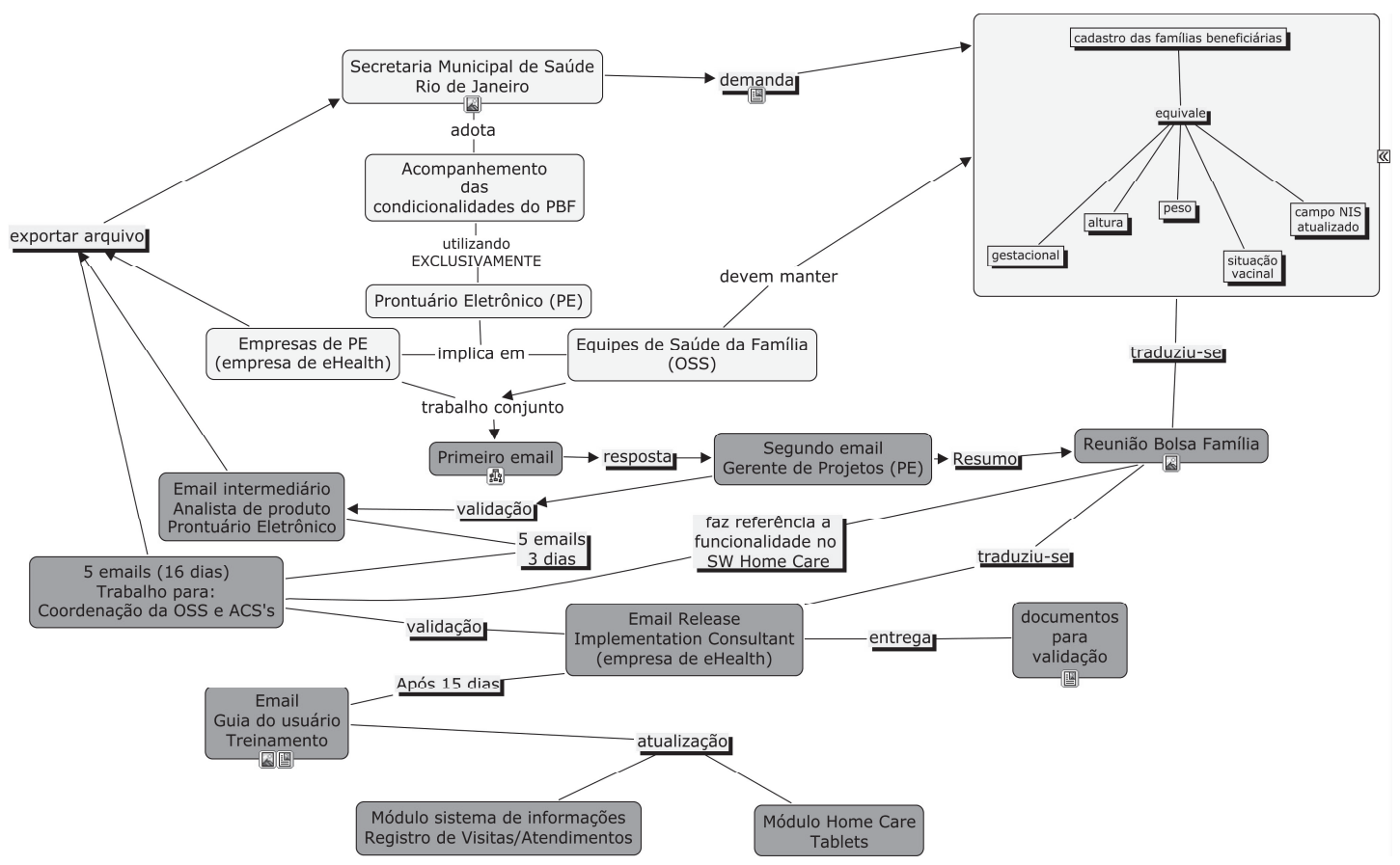

Figura 6: Mapeamento da Colaboração em Engenharia de Software em um ecossistema digital da Saúde da Família

\section{Mapeando a colaboração}

No caso estudado, tendo como base o CollabMM (MAGDALENO et al., 2009), tentamos identificar características de colaboração - que neste modelo procuram determinar níveis de maturidade de colaboração em processos de uma organização (Figura 7).

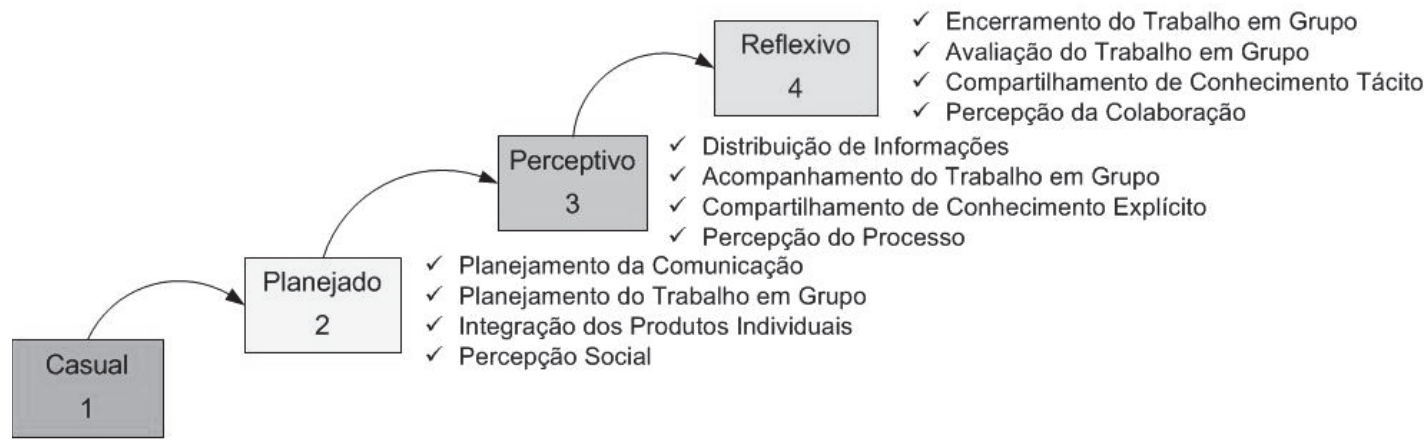

Figura 7: Níveis de Maturidade do CollabMM (MAGDALENO et al., 2009)

Inicialmente, é preciso problematizar o que seria a organização neste exemplo prático. Aqui a organização não é a fundação, nem a OSS, nem a própria empresa de eHealth, nem a SMSDC. A "organização" seria, simplificando, uma estabilização temporária da rede de interessados na construção da solução de sistemas para apoio às atividades de saúde da família. Vimos que essa rede passou por muitas configurações.

Pelo enquadramento do CollabMM (MAGDALENO et al., 2009), em relação ao que apreendemos nas entrevistas e na análise do material de comunicação e de registros sobre os requisitos, poderíamos dizer que a rede estudada estaria no nível 1, o Casual, pois não foi percebida nenhuma preocupação explícita com a estruturação da colaboração em si. 
Entretanto, foi possível observar várias estabilizações de processo colaborativo com características relacionadas aos outros níveis de maturidade do CollabMM. Um primeiro exemplo é o da estrutura de coordenação do processo de customização do software. A primeira coordenadora centralizava as ações para manter a colaboração entre as várias equipes, o que caracterizaria o nível 2 - Planejado do CollabMM. Já o segundo coordenador mostrou delegar e dar mais autonomia às equipes (por exemplo: percebemos que os técnicos de TI da OSS têm relacionamento direto com os desenvolvedores no exterior). Neste caso, teríamos características do nível 3 Perceptivo. Além disso, o novo coordenador estimulou os atores da rede a se preocuparem em direcionar e-mails e outras formas de comunicação para todos os interessados no assunto, ou requisito, que estava sendo tratado. A percepção das contribuições e dos resultados gerados pelas atividades alheias ajuda os membros do grupo a oferecer contribuições com maior segurança quanto à necessidade e relevância para o produto comum. No CollabMM, estas características de percepção indicariam o nível 2 ou até o 3. Outra característica a destacar é o sofisticado processo para integração dos produtos de cada equipe, como foi descrito no caso da customização dos sistemas para o PBF. Seriam características ao menos no nível 2.

\section{Conclusão}

Nossa pesquisa procurou, como preconiza a TAR, acompanhar descritivamente a customização de um software de eHealth no bairro estudado. Não partimos de nenhuma hipótese prévia a ser comprovada ou conceito pré-estabelecido. Esta é apenas uma entre muitas histórias, que contamos a partir da visão do ponto de entrada que escolhemos. Outras formas de abordagem são possíveis e podem ser objeto de novas investigações. Neste sentido, seria interessante acompanhar o lado dos desenvolvedores da empresa estrangeira de eHealth, passando pela sua representação no Brasil. Ou avaliar o ponto de vista dos membros das equipes de saúde da família e a percepção dos pacientes sobre o sistema. Outro ponto a aprofundar seria o estudo das outras unidades de saúde da família, que descontinuaram o uso do software. Também seria oportuno analisar essa ação coordenada público-privada de construção de um software de forma inovadora, em relação a programas estratégicos de incentivo como, por exemplo, o TI Maior.

Outra sugestão para aprofundamentos futuros é a análise dos pontos de contato que identificamos, ainda que de perspectivas distintas, entre os estudos em colaboração e os estudos CTS. Neste trabalho, em que, pudemos dialogar com várias referências dos estudos sobre colaboração em Engenharia de Software, achamos que a incorporação de ferramentas e conceitos da TAR poderia trazer contribuições importantes para este incipiente campo de pesquisa. Se por um lado, seria necessário confrontar alguns princípios básicos das duas abordagens - em especial a questão dos modelos de colaboração definidos a priori, que conflitam com a abordagem sociotécnica dos Estudos CTS -, por outro lado, seria importante a tentativa de uma conciliação ou complementaridade entre essas metodologias. Por exemplo, partindo da hipótese de que uma operação de tradução é pré-requisito para que surja a colaboração, então a TAR seria uma importante ferramenta para registro de linhas de interesses partilhados. Assim, podemos indicar alguns pontos que precisariam ser alinhados.

Por exemplo, segundo a abordagem do CollabMM, haveria um caminho de evolução progressiva através dos níveis de maturidade em colaboração (MAGDALENO et al., 2009). Esse é um ponto interessante de trazermos à discussão. No caso específico 
do nosso estudo, não identificamos um processo evolutivo da rede de colaboração como um todo, principalmente porque esse próprio "todo" está em constante transformação. Descrevemos os atores em questão criando uma estrutura organizacional situada, que não foi concebida em estrutura formal, mas que nós, a posteriori, fomos capazes de desenhar. Por outro lado, os recursos analíticos do modelo CollabMM podem ser mais eficientes no que tangem às peculiaridades de ecossistemas digitais mais estruturados ou em ecossistemas que possuam as duas características simultaneamente.

\section{Referências}

Araujo, R. M.; Borges, M. R. S., 2007, The role of collaborative support to promote participation and commitment in software development teams, Software Process: Improvement and Practice, v. 12, n. 3, p. 229-246.

Callon, M., 1986, Some elements of a sociology of translation: domestication of the scallops and the fishermen of St Brieuc Bay. In: LAW, J. (Org.) Power, action and belief: a new sociology of knowledge? London: Routledge, 1986, p.196-223.

Damian, D.; Kwan, I.; Marczak, S., 2010, Requirements-Driven Collaboration: Leveraging the Invisible Relationships between Requirements and People, In: Mistrík, I., Grundy, J., Hoek, A., et al. [orgs.] (eds), Collaborative Software Engineering, Berlin, Heidelberg: Springer Berlin Heidelberg, p. 57-76.

Fornazin, M.; Joia, L. A., 2013, Remontando a rede de atores na implantação de um sistema de informação em saúde. In: IV Encontro de Administração da Informação EnADI. Bento Gonçalves/RS.

Fuks, H.; Raposo, A. B.; Gerosa, M. A., 2003, Do Modelo de Colaboração 3C à Engenharia de Groupware. Simpósio Brasileiro de Sistemas Multimídia e Web (WEBMIDIA) - Trilha Trabalho Cooperativo Assistido por Computador (CSCW), p. 1-8, Salvador, BA, Brasil.

Hansen, M. T., 2009, When Internal Collaboration Is Bad for Your Company, Harvard Business Review, v. 84, n. 3, pp. 83-88.

Haux, R., 2005 Health Information Systems-past, present, future. International journal of medical informatics [S.I.], v. 75 p. 268.

Latour, B., 1996, Joliot: a história e a física misturadas, In: Serres, M., Gonçalves, R., Elementos para uma história das ciências, Mem Martins Terramar, pp. 131-155.

Latour, B., 2000, Ciência em Ação: como seguir cientistas e engenheiros sociedade afora. São Paulo, Editora UNESP.

Magdaleno, A. M., 2013, COMPOOTIM: Em Direção ao Planejamento, Acompanhamento e Otimização da Colaboração na Definição de Processos de Software. Tese de Doutorado, COPPE/UFRJ, Rio de Janeiro, RJ, Brasil - Capítulo 2.

Magdaleno, A. M.; Araujo, R. M.; Borges, M. R. S., 2009, "A Maturity Model to Promote Collaboration in Business Processes", International Journal of Business Process Integration and Management (IJBPIM), v. 4, n. 2, p. 111-123.

Whitehead, J.; Mistrík, I.; Grundy, J.; et al., 2010, Collaborative Software Engineering: Concepts and Techniques, In: Mistrík, I., Grundy, J., Hoek, A., et al. (eds.), Collaborative Software Engineering, v. 1, p. 1-30. 